\title{
Una obra de Luciano Salvador Gómez en el Museo de León
}

Luis Grau Lobo

Museo de León

RESUMEN. Una obra inédita y firmada del pintor barroco valenciano Luciano Salvador Gómez ha ingresado en el Museo de León procedente de colección particular leonesa, siendo restaurado de inmediato. Con ese motivo se repasa de forma sucinta lo que actualmente se conoce de la producción y personalidad del artista, escasamente delimitado por la historiografía y asociado a la obra de su hermano Vicente, así como la descripción del tema del cuadro y algunas de sus implicaciones.

Palabras clave: Pintura barroca, Valencia, Salvador Gómez, Asunción, Inmaculada.

ABSTRACT. A unpublished painting signed by a Valencian Baroque artist, Luciano Salvador Gómez, come into the Museo de León from a personal collection, and it's been restored in 2000. Because of this, a briefly review is make about his training, works, and the subject of this painting.

Key words: Baroque painting, Valencia, Salvador Gómez, Assumption, Immaculate Conception.

La utilización de las fuentes impresas, como inspiradoras de composiciones pictóricas, es un hecho más que probado Durante el pasado año $2000^{1}$ ingresó en el Museo de León un cuadro de notables di-

${ }^{1}$ Procede de la colección particular de don Fernando Geijo, donada a la administración regional a partir de la venta del palacio de los Quiñones en Riolago de Babia (León) y compuesta de numerosos objetos etnográficos, armas, relojes, etc. entre los que se encontraban diversos cuadros. La procedencia de tales piezas es incierta, pues se adquirieron en el mercado de antigüedades durante varias décadas. Concretamente éste se compró a un galerista de Madrid hace unos quince o veinte años, según amable información de don Fernando (quien ya había advertido sobre la firma de "un pintor valenciano", sin que pudiéramos contrastar tal dato físicamente de forma concluyente).
}

mensiones $(188 \times 145 \mathrm{~cm})$ cuya adjudicación definitiva a un pintor del barroco levantino ha podido establecerse como consecuencia de los trabajos de restauración en él ejecutados con ese motivo². El tema de este óleo sobre lienzo es, aparentemente, la Asunción de la Virgen, aunque, como suele suceder, contaminaciones iconográficas de temas

\footnotetext{
-

2 Trabajos realizados en 2001 por la empresa astorgana Proceso Arte 8, a la que agradecemos la puntual comunicación de la evolución del cuadro. La obra fue incluida en la exposición Tránsito (depósitos, donaciones y compras, 1999-2001), llevada a cabo en el Museo en diciembre de 2001 y enero de 2002, motivo con el que el autor de esta noticia publicó un sucinto comentario acompañado de fotografía en color de la misma para el políptico informativo, que sepamos la única publicación de este cuadro.
} 
afines permiten intuir en el lienzo la alusión, cuando menos, a otros dos asuntos marianos.

La escena se compone a partir del recurso muy barroquizante de dominar el espacio central con el cuerpo de la Virgen en un movimiento de torsión helicoidal que remarca su carácter ascendente y que se ve acentuado por el manto azul intenso que ondea a su diestra ${ }^{3}$. María viste, además, túnica roja (como es tradicional) ceñida por cinturón broncíneo con hebilla de cabeza alada de angelote ${ }^{4} \mathrm{y}$ su escote está orlado de perlas (las "perlas de tu collar" del Cantar, 4,9), así como el manto. Su cabeza está nimbada de las doce estrellas, símbolo apostólico ${ }^{5}$. Se yergue sobre nubes y creciente lunar y tanto éstas como su derredor están poblados de figuras angélicas, bien niños erotes (los consabidos putti), o cabezas aladas, uno de los cuales sostiene los lirios o azucenas, a nuestra izquierda, mientras a su vera otro sujeta el espejo ovalado "sin mancha". Entre ellos una cinta flamea

${ }^{3}$ Un recurso ampliamente documentado en la segunda mitad del siglo que, junto a la extensión del manto a la derecha de la imagen ocupando como contrapunto la escena, ya se nos ofrece, por ejemplo, en la Inmaculada de Murillo, inmaculadista por antonomasia, del Museo de Bellas Artes de Sevilla, y así se dispone en el cuadro referente y precursor de este modelo, la Inmaculada de Ribera para las agustinas de Monterrey en Salamanca y que contrasta con las versiones más escultóricas y contenidas de la primera mitad.

${ }^{4}$ Cinturón que tal vez recuerda la leyenda de la Madonna della cintola, culto muy querido en Toscana -donde se desarrolló una iconografía específica- según el cual y desde los cielos, la Virgen arrojó su cinturón para convencer al escéptico Tomás de su Ascensión a los cielos. Véase RÉAU, L.: Iconografía del arte cristiano, 1.2, Nuevo Testamento, Madrid, 1996, pp. 640-641.

${ }^{5}$ Aunque STRATTON, S.: La Inmaculada Concepción en el arte español, Madrid, 1989, pp. 97-107 mantiene que tuvieron en la España del XVII y XVIII un sentido devocional, no exento de polémica: el Stellarium, recuerdo de que debían rezarse doce Avemarías y tres Padrenuestros, así como reflexionar sobre determinados asuntos marianos. con la leyenda: "Splendor Patris", lugar de destino.

La perspectiva aérea permite contemplar en las esquinas inferiores sendos paisajes difuminados por la propia pincelada y por el deterioro del lienzo: una especie de jardín (el "huerto cerrado") con una escalinata (la "escalera de Jacob"), una posible torre (la de David) y al menos un ciprés (el de Sión) a nuestra izquierda y, en el lado opuesto, difícilmente se distingue un puente de piedra (¿alusión al "manatial de aguas vivas"?) de arcos de medio punto sobre un cauce de agua y una posible ciudad (civitas dei), al fondo. Todos ellos, $\mathrm{y}$ quizás alguno más que resulta inapreciable dada la conservación del óleo, son símbolos tomados de las letanías de la Virgen y difundidos a partir del desarrollo del misterio por medio de textos del Cantar de los Cantares y de los exégetas ${ }^{6}$, ya desde el $\mathrm{XV}$, que el pintor barroco ha integrado en el cuadro como paisaje y aderezo icónico.

Mientras tanto, en las esquinas superiores se desarrolla el universo celestial: a nuestra izquierda el cortejo de ángeles músicos, en diversas posturas y provistos de trompas, entre los que destaca uno de los más próximos a María, que tañe un instrumento de cuerda, especie de laúd o vihuela. Junto a éste, un angel niño porta una corona, desproporcionada por su pequeño tamaño, que más parece un símbolo que el posible tocado de la Virgen en una supuesta Coronación. Al otro lado, hacia donde dirige su vista la Asunción, Dios Padre bendice y sujeta la esfera del mundo, mien-

\footnotetext{
${ }^{6}$ Así, María tota pulchra es "Sol, stella, luna, porta caeli, lilium inter spinas, speculum sine macula, hortus conclusus, fons signatus, civitas dei..." según las recomendaciones de Molanus en 1568, véase STRATTON, ob.cit., p.34 y ss. y, de todas formas, la mayoría de los símbolos pueden hallarse en las metáforas descriptivas de la amada en el Cantar.
} 
tras la paloma del Espíritu santo aletea entre los rayos de luz.

Así las cosas, el asunto de la obra parece debatirse entre determinados momentos de la vida de María cuya transposición iconográfica, amén de haberse formado lentamente $\mathrm{y}$, en ocasiones, sin apoyo textual canónico ${ }^{7}$, sufrió frecuentes mixturas. Por una parte la Asunción, derivada de la Ascensión y Resurrección, de forma que el cuerpo de María no asciende a los cielos per se, sino por impulso de otros (ángeles), pues se trataría de una ascensión pasiva, no activa como sucedía con la de su Hijo. Por otro lado, la Coronación, momento inmediatamente posterior, es aquí insinuada por el ángel que sostiene la misma, aún sin situarla sobre su cabeza, por otra parte aureolada de estrellas ${ }^{8}$. Y, finalmente, como no podía ser de otra forma, la Inmaculada, cuyo desenvolvimiento, muy prolífico en el arte hispano, recurre a préstamos de estos temas similares en la formalización imaginera de un dogma cuya aprobación muy tardía no impidió una fecunda representación artística, posiblemente más fácil y efectiva de defender a través de la imagen devocional que de los textos sagrados ${ }^{9}$.

${ }^{7}$ El propio VORÁGINE, S.: La leyenda dorada, ed. cast. Madrid, 1982, pp. 477-498, confiesa, para empezar, y en otras partes del texto, lo apócrifo de sus fuentes. En la misma obra, un autor posterior de una de las adiciones al tratado, que escribe posiblemente en el siglo XV -centuria significada en la defensa del nuevo dogma y formación de su imaginería- demuestra especial beligerancia en la autentificación del culto concepcionista, que aunque posterior a las Escrituras, se instala el 8 de diciembre gracias a diversas apariciones marianas y otros argumentos teologales y conciliares (pp. 850-861).

${ }^{8}$ En este sentido cabe recordar que la Coronación puede estar realizada por un ángel, o por el propio Cristo, y en su máxima complejidad, acompañado por la Trinidad. Faltaría, pues, en este caso, la figura del Hijo de María.

${ }^{9}$ Ya RÉAU, ob.cit. pp. $81-90$ y p. 639 , afirma que la Assumpta tiende a confundirse con la Inmaculata, aun-
La limpieza de la obra, afectada por craqueladuras, desprendimientos y abundante suciedad, reveló fehacientemente la firma del artista, centrada en la parte inferior del lienzo y que, aunque semiperdida por el deterioro de la pintura, permite leer sin problemas "Luciano Salvador y G(ómez)", resultando el segundo apellido parcialmente ilegible, aunque fuera explícito.

Luciano Salvador Gómez ya aparece citado por Orellana y Ceán Bermúdez ${ }^{10}$. Pintor afincado en Valencia y activo al menos en el tercer cuarto del siglo XVII, pertenece a una saga de pintores del país, hijo de Pere Salvador y hermano del más cualificado pintor, dibujante, académico y tratadista Vicente Salvador Gómez ${ }^{11}$, discípulo de

que esta última sea, en puridad, un descendimiento, significativo de la concepción de María sin pecado original, que fue representada anteriormente por medio del abrazo de sus progenitores en la Puerta Dorada. La declaración universal del dogma no fue aprobada hasta 1854 y cabe recordar, a estos efectos, que no sólo ascendió a los cielos el alma, sino también el cuerpo de María, incorruptible desde su concepción. La trascendencia de las propuestas pictóricas del barroco hispano para la canonización del voto inmaculadista tienen infinidad de ejemplos, entre los que cabe señalar el enorme alegato que realizó en 1616 el pintor y clérigo Juan de Roelas sobre la procesión sevillana del año anterior, conservado en el Museo Nacional de Escultura de Valladolid, o la propia teorización de PACHECO, que sanciona la asociación con la Mulier amicta sole del Apocalipsis, ver su Arte de la pintura, su antigüedad y su grandeza..., Sevilla, 1649, ed. de Sánchez Cantón, Madrid, 1956, p. 209 y ss.

10 CEÁn Bermúdez, J.A.: Diccionario histórico de los más ilustres profesores de las bellas artes en España, tomo IV, Madrid, 1800, p. 315 y ORELLANA, M.A.: Biografía pictórica valenciana, Ed. de Xavier de Salas, Valencia, 1967, pp. 272-274, ambos citan varias obras y su costumbre de firmarlas.

${ }^{11}$ Aparte las menciones antiguas, este último pintor ha sido objeto de delimitación más cercana por parte de PÉREZ SÁNCHEZ; A.E.: "Vicente Salvador Gómez. A propósito de una obra adquirida para el Prado", Boletín del Museo del Prado, tomo I, no 2, 1980, pp. 69-78, que cita la bibliografía previa sobre el mismo, al que hay que añadir la inclusión de ese cuadro en la colección de Godoy, según Rose, I.: "Una nota sobre la "Expulsión de los mercaderes del templo" de 
Jerónimo Jacinto Espinosa y heredero en última instancia de la gran escuela valenciana formada a la sombra italiana del Españoleto y de los Ribalta. Sus obras, como su personalidad artística, distan de ser correctamente conocidas, aunque algunas de ellas han merecido figurar entre los manuales al uso sobre la pintura barroca española ${ }^{12}$, siendo comúnmente asociado en la historiografía a la obra de su hermano, quien factiblemente conectó en Italia con su paisano Vicente Giner y se formó en una vanguardia pictórica que no llegó a desarrollar

Vicente Salvador Gómez", en el mismo Boletín del Museo del Prado, t. III, no 9, 1982, pp. 191-192. También puede verse EsPiNós, A.: Dibuixos valencians del Segle XVII, Valencia, 1994, pp. 158-159 o, para aspectos más concretos, GARCíA MAHIQUES, R.: “Vicente Salvador Gómez y la iconografía de San Ignacio de Loyola en la Casa profesa de Valencia", Boletín del Museo e Instituto Camón Aznar, no LXIII, 1996, pp. 57-78 (donde se subraya su uso iconográfico de grabados) e ID.: "La iconografía emblemática de la Sangre de Cristo. A propósito de una pintura inédita de Vicente Salvador Gómez", en el mismo Boletín, no LXVIII, 1997, pp. 63-106. Su biblioteca (incrementada con la de Alonso Cano) así como detalles significativos de su biografía y formación, han sido objeto de estudio más reciente por parte de NAVARRETE, B.: "Sobre Vicente Salvador Gómez y Alonso Cano: nuevos documentos y fuentes formales", Ars Longa, no 6, Valencia, 1995, pp. 135-140, y SALORT, S.; LÓPEZ AZORÍN, M.J. y NAVARRETE, B.: "Vicente Salvador Gómez, Alonso Cano y la pintura valenciana de la segunda mitad del siglo XVII", Archivo Español de Arte, 296, 2001, pp. 393-424. Lo conservado de su Cartilla y fundamentales reglas de la pintura ha sido recogido en varios trabajos (ver nota 15 de Navarrete, 1995) aunque fundamentalmente en ANGULO Y PÉREZ-SÁNCHEZ, Corpus of Spanish Drawings, vol 4, Londres, 1988, no 402-407.

12 ANGUlo, D.: Pintura española del siglo XVII, Ars Hispaniae, XV, Madrid, 1971, pp. 330- 331 cita curiosamente una Concepción firmada por Luciano en la colección del Marqués de Almunia que no aparece representada, cuya sumaria descripción se aproximaría a la nuestra en sus maneras "rubenianas" dispares de la supuesta formación del artista. PÉREZ SÁNCHEZ, A.E.: Pintura barroca en España (1600-1750), Madrid, 1992, p. 391, ilustra en p. 389 una Asunción o Resurrección de María, de colección privada madrileña -¿la misma?-, en la que figuran, ahora inequívocamente, tanto el sepulcro como los apóstoles testigos del acontecimiento. a causa de su temprano fallecimiento a los 41 años, en 1678. La obra de Luciano es, empero, más escolástica, habitualmente ceñida a la transposición de estampas de culto, bien rubenienas bien italianas, como afirma Pérez Sánchez ${ }^{13}$, en las que intentó, con escasa trascendencia, la adaptación del tradicional naturalismo valenciano a las maneras del pleno barroco.

En nuestro cuadro color y pincelada, aunque efusivos y provistos de arabescos formales que llegan a preponderar sobre la inclusión de los símbolos parlantes, en un esquema compositivo muy característico del último tercio del siglo ${ }^{14}$, los rigores espinosianos dominan el pincel: empastes sólidos y definición dibujística no ceden ante la pincelada suelta de la época y se carece de un trabado aliño compositivo, bien evidente en las deficiencias de una espacialidad a la que se aspira. La estricta división en dos planos paralelos resta monumentalidad, pese a las dimensiones del lienzo, al gran tamaño de la figura protagonista y la carencia de profundidad concede escasa verosimilitud a las figuras superiores impidiendo que el pintor realice una correcta lectura de la componente "atmosférica" y que la corpórea figura de María tenga ubi-

${ }^{13}$ De hecho así lo hacía su hermano Vicente tal como ha podido demostrar NAVARRETE, ob.cit., 1995, siguiendo estampas preferentemente italianas (Cort, Schamocci o Agostino Carracci, por ejemplo), aparte del influjo de Alonso Cano.

${ }^{14}$ Así, aunque el exemplum siga siendo la citada obra de Ribera pintada en 1635, también pueden aludirse las versiones más cercanas en el tiempo del gran inmaculadista hispano José Antolínez, e incluso a Rizi, en una producción incrementada en estas fechas a raíz de la expansión del culto promovida por la bula del Papa Alejandro VII Sollicitudo omnium Ecclesiarum, del 8 de diciembre de 1661. La concesión a España, tres años más tarde, del derecho a celebrar de precepto misa y oficio a este culto y los consiguientes fastos locales, uno de los cuales dio lugar, precisamente en Valencia, a un libro titulado Solemnes fiestas a la Inmaculada Concepción (1663), nos sitúa en un ambiente propicio para el encargo de este lienzo. 
cación en el telón de fondo etéreo que la acompaña. Se trata, por tanto, de una versión local, limitada pero no exenta de interés por adaptar las corrientes en boga del espléndido periclitar de la pintura barroca española del XVII.

En definitiva, una nueva incorporación al catálogo de pinturas del Museo leonés que desde que fuera confeccionado $\mathrm{y}$ publicado hace siete años ${ }^{15}$ ha visto incrementados sus fondos sorprendentemente para lo que suele ser hábito en nuestros museos provinciales, con al menos quince nuevas obras pictóricas ${ }^{16}$.

${ }^{15}$ GONZÁlez CHAO, M.C.: Catálogo de pinturas del Museo de León, León, 1995. Es destacable a este respecto que, frente a lo que sucede en muchos de los museos provinciales, la colección pictórica leonesa no se nutre de ningún depósito del Museo del Prado.

${ }^{16}$ Alguna tan notable como la tabla del Maestro de Astorga estudiada en GRAU LOBO, L.: "Noticia de una nueva pintura en el Museo de León: peregrinos ante el altar de Santiago", Brigecio, no 6, 1996, pp. 103-110, aparte de los cuadros de la misma colección, de desigual factura y todos inéditos, que sepamos, algunos de ellos en fase de restauración y estudio. 


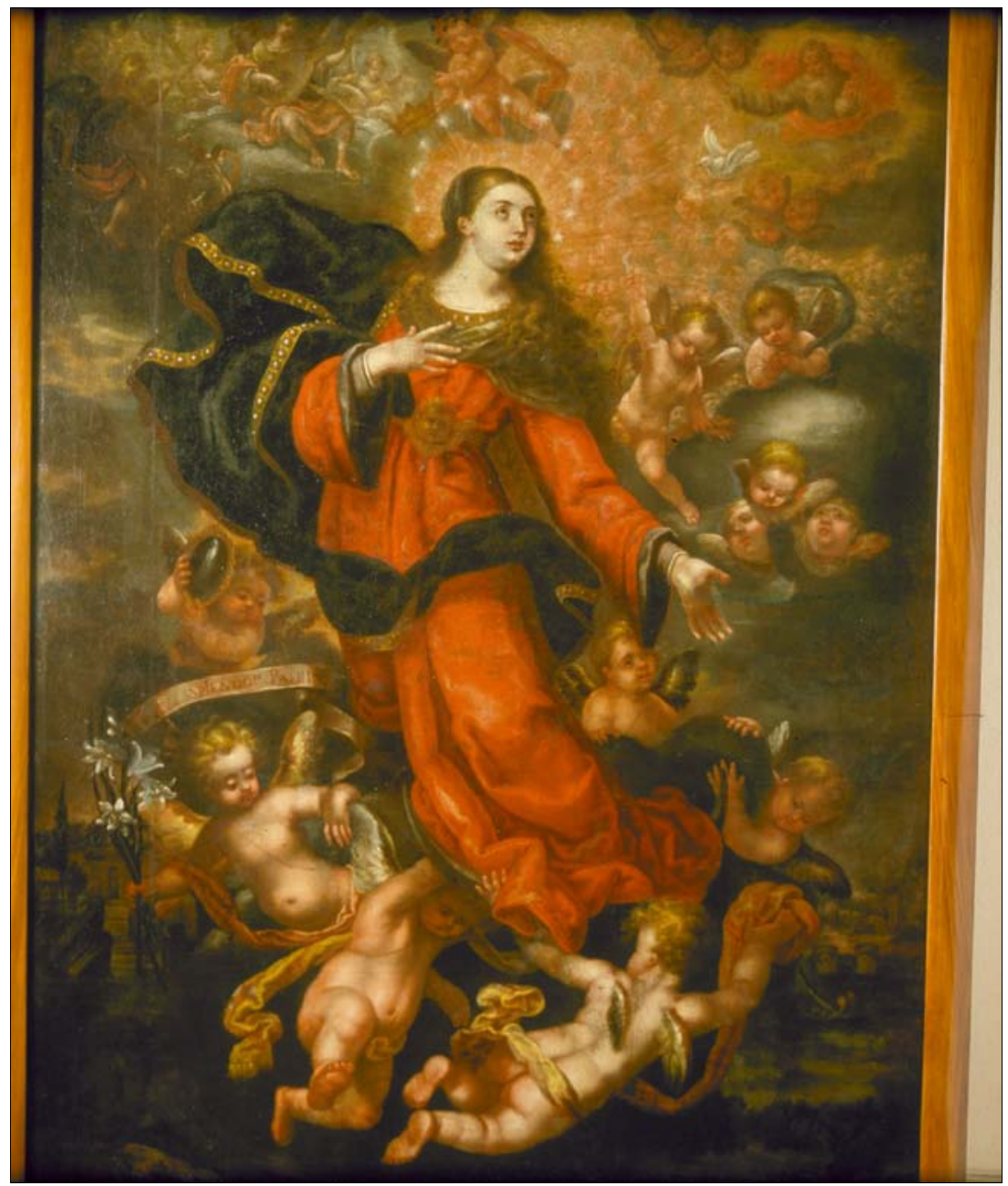

- Fig.1. Asunción de la Virgen. Luciano Salvador Gómez. (arriba centro) 